\title{
A identificação do sujeito pós-moderno na literatura contemporânea de Markus Zusak: análise das personagens de Cartas Cruzadas
}

Rusanil dos Santos Moreira Júnior ${ }^{1}$

Laureny LourençO²

\begin{abstract}
RESUMO: O presente artigo propõe-se a examinar o caráter pós-moderno da obra australiana Cartas Cruzadas, de Markus Zusak, a qual apresenta questões pertinentes à contemporaneidade e, em especial, à configuração do sujeito pós-moderno, que é o nosso objetivo. O conceito que adotamos sobre pós-modernismo e de sujeito pós-moderno tem como principal base teórica os estudos de Linda Hutcheon (1991) e de Stuart Hall (2004), nos quais fundamos os nossos pensamentos críticos. Em Cartas Cruzadas, Ed Kennedy, personagem protagonista, é submetido a missões em que, na realização delas, é possível compreender a caracterização do pós-moderno na sociedade contemporânea e identificar elementos peculiares ao pós-modernismo. Será através da análise dessa personagem, de Marv e de Audrey, dialogando com as teorias de autores como Teixeira Coelho (2005), Fredic Jameson (2005), Umberto Eco (1985), entre outros, que compreenderemos os sujeitos híbridos em estudo. Além disso, subsidiando-nos na teoria de Antonie Compagnon (2006) a fim de chegar a algumas considerações sobre a literatura contemporânea, a partir das conclusões deste estudo.
\end{abstract}

Palavras-chave: pós-modernidade; literatura contemporânea; romance; identidade; personagens.

\section{The identification of the post-modern subject in contemporary literature by Markus Zusak: analysis of characters of Cartas Cruzadas}

\begin{abstract}
This paper seeks to examine the post-modern character of the Australian work Cartas Cruzadas, by Markus Zusak, which presents issues relevant to contemporaneity and in particular, the configuration of the post-modern subject. The concept we take on postmodernism and the postmodern subject is based on the theoretical studies of Linda Hutcheon (1991) and Stuart Hall (2004), in which we founded our critical thoughts. In Cartas Cruzadas, Ed Kennedy, the protagonist character, is subjected to missions in which, in performing them, one can understand the characterization of the postmodern in contemporary society and identify peculiar elements of postmodernism. Through the analysis of characters like Marv and Audrey, as they discuss theories by authors such as Teixeira Coelho (2005), Fredic Jameson (2005), Umberto Eco (1985), among others, we begin to understand the hybrid subjects in study. In addition, we develop come considerations on contemporary literature through Antonie Compagnon's theory (2006) as we conclude this study.
\end{abstract}

Keywords: postmodernity; contemporary literature; romance; identity; characters.

\footnotetext{
${ }^{1}$ Mestrando do Programa de Pós-Graduação em Letras e Linguística da Faculdade de Letras da Universidade Federal de Alagoas (PPGLL/FALE/UFAL). E-mail: rusanil.moreira@hotmail.com ${ }^{2}$ Doutora em Estudos Literários. Professora Adjunta da Faculdade de Letras da Universidade Federal de Alagoas (FALE/UFAL). E-mail: laurenylourenco@yahoo.com.br
} 


\section{INTRODUÇÃO}

A escrita tem horror ao vazio: o vazio é o lugar do morto, da falta. A literatura é uma inevitável petição de princípio. Literatura é literatura. (Antoine Compagnon)

No estudo da Literatura, tradicionalmente, é comum a reflexão e análise de obras canônicas, isto é, aquelas que têm um olhar privilegiado pela Academia. Até os dias de hoje, são tidas como singulares pelos estudiosos da área e concebidas como referência quanto à qualidade dos textos literários e ao reconhecimento como boa obra literária. Por conseguinte, elas são chamadas de clássicas e recorrentemente estudadas. No entanto, muito se tem escrito após os grandes clássicos, inclusive, na literatura contemporânea. Essa possui uma exorbitante quantidade de leitores, que aumenta a cada dia, devido à configuração literária proposta por suas obras. Contudo, ela é vista como literatura menor ou até mesmo não chega a ser nomeada como literatura.

No sentido de valorizar a literatura contemporânea e a riqueza literária nela presente, a escolha do romance Cartas Cruzadas e do tema adveio, primeiramente, do interesse em analisar um livro que não fosse clássico e de estudar uma narrativa que não estivesse escrita em sua versão original (o inglês), ou seja, trataremos da tradução ${ }^{3}$ em língua espanhola, de Matuca Fernández de Villavicencio. Além disso, a referida obra foi publicada recentemente, em 2002, logo, é provável que haja poucos estudos acerca dela. No ano seguinte, ganhou o prêmio da melhor novela juvenil da Austrália. Ao que se refere ao autor da obra, ele é um jovem e contemporâneo

\footnotetext{
${ }^{3}$ Todas as traduções neste artigo realizadas são de nossa autoria e, portanto, de nossa responsabilidade.
} 
australiano, que foi concebido como um dos mais inovadores e poéticos romancistas da atualidade, com a publicação de A menina que roubava livros. Além disso, o referido escritor foi batizado como "fenômeno literário" por críticos australianos e norteamericanos, o que o caracteriza como um escritor relevante para a literatura da atualidade.

Neste artigo, realizamos uma análise do sujeito pós-moderno nas personagens Ed Kennedy, Marv e Audrey da narrativa zusakiana Cartas Cruzadas. Com base nessa análise, caracterizamos a configuração do sujeito pós-moderno a partir do estudo das personagens supracitadas, correlacionamos a concepção de sujeito pós-moderno da sociedade contemporânea à configuração das personagens da narrativa em estudo e explicamos a compreensão da significação estética do romance zusakiano, a partir de aspectos característicos da narrativa.

O objetivo de estudar as personagens da obra em questão deve-se ao fato de que são as que com mais nitidez tornam patente a ficção. Além disso, são as maiores responsáveis pela força e eficácia de um romance. Ou seja, por meio delas podemos identificar o contexto de uma sociedade e a configuração dos seus sujeitos (BRAIT, 1985). Além disso, estamos cientes de que Cartas Cruzadas possui um elenco de personagens que se caracteriza por ter uma identidade que se desvia dos padrões habituais, isto é, diferencia-se daquelas personagens que comumente encontramos nas obras modernas e que, à mesma medida, aproxima-se da realidade da sociedade contemporânea.

\section{CARTAS CRUZADAS: A HISTÓRIA DE ED KENNEDY}

Cartas Cruzadas conta a história de um jovem comum chamado Ed Kennedy, de dezenove anos de idade, do subúrbio de uma cidade grande, o qual narraa sua própria história, já que a narrativa está predominantemente escrita na primeira pessoa do singular. 
A narrativa começa em um banco quando esse jovem, Ed Kennedy, e seus amigos são surpreendidos por um assalto. Toda a situação poderia gerar um grande problema, mas, em virtude de um cúmulo de situações fortuitas, o assalto não tem sucesso e, no fim, detêm-se o assaltante. Da noite para o dia, Ed se converte em uma espécie de herói local. Dias depois, esse jovem recebe em sua caixa de correio tradicional ${ }^{4}$ uma misteriosa carta. No interior dessa carta, está um naipe com uma lista de endereços escritos nele. Ed não conhece tais endereços e menos quem os enviou. Após uma investigação - sem sucesso - sobre o suposto remetente e umas visitas aos endereços recebidos, o suburbano compreende que tem uma missão ${ }^{5}$, ainda que não entenda o porquê de toda a situação. Essa missão consiste em ajudar, como ele puder, as pessoas desses endereços, permeada de surpresas e histórias paralelas. Isto é, cada história possui uma evolução diferente, com início, meio, mas que não parecem ter um fim, pois, ainda que aquela missão acabe, Ed não a considera como uma missão terminada ${ }^{6}$, porém como uma história que agora faz parte da sua. Além disso, nenhuma dessas histórias correlaciona-se entre si, cada história é um caso particular. No entanto, apesar de serem reservadas, elas predominam até o final da narrativa através das lembranças de Ed e da presença dele na vida dessas pessoas. Por fim, a cada vez que Ed Kennedy consegue resolver a incógnita do naipe recebido, ele é surpreendido com outro, totalizando cinco até o final da obra.

O romance em questão possui várias personagens, cada uma com sua significância e importância para a sucessão e compreensão dos aspectos que aqui serão tratados. No entanto, delimitar-nos-emos à análise das personagens Ed

\footnotetext{
${ }_{4}^{4}$ Trata-se de um correio clássico, isto é, residencial, no qual recebemos todos os tipos de correspondências.

${ }^{5}$ Quando tratarmos de "missões", estamos referindo-nos a situações em que Ed Kennedy tem o compromisso de desvendar os possíveis problemas de pessoas pré-determinadas através dos naipes que ele recebe. Nessas missões, de alguma maneira, ele tem que ajudar a essas desconhecidas pessoas, ainda que Ed Kennedy não buscasse tais missões e não entendesse a finalidade delas.

${ }^{6}$ Consideramos "terminada" como "descartável", "irrelevante", em que já não the serve, não the importa.
} 
Kennedy, Marv e Audrey. A escolha delas deve-se ao fato de que a primeira é a personagem principal e as duas últimas têm um grande vínculo afetivo com a primeira e estão muito presentes na narrativa. Além disso, cada uma delas possui uma identidade que ao mesmo tempo assemelham-se e diferenciam-se, próprio do sujeito pós-moderno. Assim sendo, faz-se necessária uma breve apresentação de tais personagens.

\subsection{Ed Kennedy}

Um adolescente comum, de um bairro pobre de uma grande cidade. Vive em um apartamento alugado em péssimas condições. Com ele, vive um cachorro fétido chamado Doorman, de dezessete anos de idade. Sustenta-se a partir do que ganha com seu emprego em uma empresa de táxis. Sem grandes perspectivas de vida, Ed é um jovem angustiado pela morte de seu pai, pelo rechaço de sua mãe, pelos seus fracassos na vida, pelas missões que tem que cumprir e pela incapacidade de ter o amor de Audrey, sua grande amiga, apesar de tê-lo tão perto. Tudo isso corrobora para a sua frustração existencial, "sem muitas perspectivas nem possibilidades" (ZUSAK, 2002, p. 14, tradução nossa). Diariamente, o tenro Kennedy é acostumado a jogar cartas com seus amigos, esse é o seu maior e melhor passatempo. Sempre está acompanhado de Marv, Audrey e Ritchie, amigos que também não demonstram consideráveis perspectivas de vida.

\subsection{Marv}

Amigo de infância de Ed, tem vinte anos de idade. Vive com os seus pais e exerce a função de carpinteiro com o seu genitor. No entanto, não gasta nenhum centavo do que ganha, nem para as suas necessidades, como um cigarro, por exemplo. Como o define Ed, "Marv é o mestre da mesquinharia com o dinheiro. $\mathrm{O}$ príncipe da tacanhearia" (ZUSAK, 2002, p. 45, tradução nossa). 


\subsection{Audrey}

Grande amiga e amor de Ed Kennedy. Uma jovem muito atraente fisicamente. Tem aproximadamente a mesma idade de seus amigos. Sai com vários homens, mas se recusa a sair com Ed, pois afirma que ele é diferente, considera-o muito especial. Em todas as ocasiões parece ser a única a compreender o seu amigo Ed. Além disso, é taxista na mesma empresa em que o seu admirador trabalha.

\section{A IDENTIFICAÇÃO DOS PÓS-MODERNOS E A SOCIEDADE PÓS- MODERNA}

O jamaicano Stuart Hall (2006), grande estudioso da identidade do sujeito pós-moderno, defende que essa não é permanente, unificada, "resolvida", tampouco palpável, por isso, "em vez de falar da identidade como uma coisa acabada, deveríamos falar de identificação, e vê-la como um processo em andamento" (p. 39). Dessa maneira, quando tratarmos da identidade, estamos considerando esta conceituação que nos diz Hall (2006), isto é, como algo que está em constante construção, fragmentado, nunca acabado, mas, sim, remodelado, que nunca estará totalmente elaborado.

Nesse sentido, faz-se necessário que exponhamos o que consideramos como pós-moderno. Como afirma Cabral (1999), a pós-modernidade é um labirinto de significações, ou seja, dependendo dos paradigmas que levamos em conta, o seu significado e os seus referenciais mudam. Dessa forma, a política, a história, a estética, a religião, entre outros campos do conhecimento têm as suas referências para o "moderno". Respaldando-nos nesse autor, trataremos o "moderno" como uma concepção de história mais dinâmica em que há a centralização sobre o indivíduo e a subjetividade, a pluralidade de sentidos e significações, modelos e padrões sujeitos a renegociações e redefinições. Com base nessa posição, é sabido que 
no mundo contemporâneo há a epistemologia da indeterminação, do pluralismo, contudo, há a acentuação da multiplicidade e a aceitação do efêmero e descontínuo, o que caracteriza o "pós-moderno", concepção também defendida por Cabral (1999). Isso posto, podemos afirmar que a pós-modernidade é uma continuidade da modernidade, no entanto, aquela é uma reação crítica a esta. Dentro dessa mesma perspectiva, Teixeira Coelho (2005) afirma que o rompimento entre essas duas é o compromisso que a pós-modernidade tem com a "realidade total", "tensionada" e "multifacetada", o que caracterizará o sujeito pós-moderno.

Corroborando com isso, Jameson (2005) e Eco (1985) estão de acordo que a pós-modernidade é uma reação à forma canônica da modernidade, opondo-se à sua preponderância, isto é, é uma atitude contra os modelos modernos, juntamente com a dissolução de fronteiras. Sob a ótica de Fredic Jameson (2005, p. 17),

[...] ele [o conceito de pós-modernidade] não é apenas mais um termo para a descrição de determinado estilo. É também [...] um conceito de periodização cuja principal função é correlacionar a emergência de novos traços formais na vida cultural com a emergência de um novo tipo de vida social e de uma nova ordem econômica.

Quanto à configuração da sociedade contemporânea, como aborda Hall (2006), ela está em constantes mudanças, as quais são rápidas, contínuas e permanentes, o que as diferencia das sociedades tradicionais em que parece haver uma uniformidade, ou seja, uma estabilidade duradoura. Nas palavras de Hall (2006, p. 15), “a modernidade [dessa sociedade] não é definida apenas como a experiência de convivência com a mudança rápida, abrangente e contínua, mas é uma forma altamente reflexiva de vida".

Correlacionando tais conceitos com as personagens em análise, o jovem Ed Kennedy, dentre suas várias características, também assume múltiplas identidades. Ao longo da narrativa, perante as diversas missões que ele tem que cumprir, elas - as identidades - se constroem em histórias distintas, paralelas, que ocorrem 
simultaneamente, isto é, estão conectadas. Em uma delas, Ed Kennedy é Jimmy para uma senhora que supostamente tem Alzheimer, em que esse Jimmy era o seu marido que havia morrido há anos. Além disso, ele é o rapaz que incentiva uma jovem corredora em suas competições e é o homem que resolveu o problema de uma pequena família composta por um pai, mãe e filha, na qual a esposa era abusada sexualmente todas as noites pelo seu marido quando este chegava embriagado dos bares, enquanto isso, a pequena criança vivia aturdida com tal situação. Essas e outras identidades que coexistem em Ed lhes dão prazer e satisfação, como a própria personagem declara:

Passei por Edgar Street várias vezes e tudo continua igual. O homem não voltou ainda. Acho que nunca voltará.

A mãe e a filha pareciam felizes nos momentos que estive observando-as. Isso me basta.

À noite vou à casa da Milla e leio para ela.

Alegra-se muito por ver-me e devo confessar-lhes que eu gosto de voltar a ser o Jimmy. Bebo chá e beijo a bochecha enrugada da Milla quando me vou.

No sábado, vou ver Sophie correr ficando em segundo lugar, mas fiel à sua palavra, corre descalça. Vê-me e assenta com a cabeça (ZUSAK, 2002, p. 144, tradução nossa).

Diante disso, Ed Kennedy assume diferentes identidades em momentos diferentes, ora é Jimmy, ora é uma espécie de incentivador da jovem corredora, ora é o salvador daquela sofrida família. Logo, Ed não possui uma identidade, mas identidades que não são unificadas ao redor de um "eu" coerente, as quais estão continuamente deslocadas, pois "esse sujeito se pulveriza. Não é mais um. São milhares, espalhados por todos os lugares" (COUTO, 2000, p. 29). Na teoria de Hall (2006),

[...] à medida que os sistemas de significação e representação cultural se multiplicam, somos confrontados por uma multiplicidade desconcertante e cambiante de identidades possíveis, com cada uma 
das quais poderíamos nos identificar - ao menos temporariamente (HALL, 2006, p. 13).

Assim como Ed, as personagens Audrey e Marv também apresentam traços do sujeito pós-moderno. Uma das características da identidade pós-moderna é a contradição (HALL, 2006), onde há a aceitação do efêmero e do descontínuo (CABRAL, 1999), uma identidade não coerente, mas geradora de significados. Audrey, facilmente tem relações sem compromisso com vários homens, no entanto, recusa-se a tê-las com o seu melhor amigo, Ed. Ela justifica o rechaço por amá-lo muito, o que a torna contraditória. "Audrey, que se deita com um monte de caras, mas nunca comigo. Diz que gosta muito para ter relações comigo e eu, pessoalmente, nunca tentei que se despisse e tremesse diante de mim" (ZUSAK, 2002, p. 31, tradução nossa). Assim como Audrey, Marv também é contraditório. Sua contradição está expressa em sua principal característica: a mesquinhez. Todo o dinheiro que ele ganha, ele o guarda no banco. Nem para as suas necessidades ele o investe. Seu carro, que está em péssimas condições de uso, nunca passou por uma reforma, apesar de Marv amar o seu automóvel. No entanto, a finalidade da quantia que ele tem investida no banco, a qual é bastante considerável, é omitida durante quase toda a narrativa.

- Por que tu não compras outro carro, filho?

Marv o olha muito sério.

- Tenho minhas razões.

- Não tens dinheiro?

- Claro que tenho. Eu trabalho, sabia? - Até consegue soar repugnante -. Mas tenho outras prioridades. - E sorri como somente alguém que está orgulhoso de um carro como o seu poderia fazê-lo. - . Além disso, adoro o meu carro.

- Certo. - conclui o policial -. Até mais (ZUSAK, 2002, p. 21-22, tradução nossa).

Além disso, na narrativa há uma simbologia ao que se refere às cinco cartas de baralho que Ed recebeu, as quais contêm, através de códigos (nomes, endereços, 
frases), as direções das suas missões. Tal jogo era o melhor e preferido passatempo das personagens, o jogo de cartas foi usado para ditas missões e que originou o título do livro na versão em espanhol: Cartas Cruzadas. Sequencialmente, o jovem Kennedy recebeu os seguintes naipes: um as de ouros, um as de paus, um as de espada, um as de coração e, por fim, um coringa.

De acordo com a cartomancia -o estudo dos significados das cartas do baralho - cada naipe possui uma interpretação, ainda que não haja uma comprovação científica acerca da sua veracidade. Sabiamente, o autor se utilizou da representação, isto é, da simbologia dessas cartas para correlacioná-las à temática da missão. Nesse sentido, percebe-se a concepção pós-moderna na literatura, a qual "supera as diatribes entre realismo e irrealismo, formalismo e 'conteudismo', literatura pura e literatura engajada, narrativa de elite e narrativa de massa" (ECO, 1985, p. 59), como exemplifica a análise da tabela 1. Nessa perspectiva, o texto narrativo não está conformado e fixado em contornos, de modo que apresenta uma margem ilimitada, "não mais considerado um valor em si, mas diluído nas malhas de outros discursos"' (SOUZA, 2002, p. 19).

Vejamos uma esquematização da representação de cada um dos naipes na tabela 1. Na primeira coluna estão denominados cada um dos naipes; na segunda, os significados de cada um deles a partir dos conteúdos extraídos das páginas web Gotach e Topgyn; por fim, na terceira, correlacionamos a simbologia dos naipes com a descrição dos episódios protagonizados pela personagem Ed na narrativa, que foram definidos desde o princípio deste artigo como "missões".

\begin{tabular}{|c|l|l|}
\hline NAIPES & \multicolumn{1}{|c|}{ SIGNIFICADOS } & \multicolumn{1}{c|}{ CORRELAÇÃO COM AS MISSÕES } \\
\hline \multirow{3}{*}{ As de ouros } & $\begin{array}{l}\text { Ed resolve o problema de uma família em } \\
\text { Ranhos trabalho, poder, } \\
\text { gatisfação e materialidade. }\end{array}$ & $\begin{array}{l}\text { que patriarca abusava sexualmente de } \\
\text { sua mulher, quando esse chegava } \\
\text { alcoolizado em casa. Dito casal possui } \\
\text { uma filha que padecia dessa situação. } \\
\text { Com o desaparecimento do patriarca, }\end{array}$ \\
\hline
\end{tabular}




\begin{tabular}{|c|c|c|}
\hline & & $\begin{array}{l}\text { mãe e filha passaram a viver em bem- } \\
\text { estar. } \rightarrow \text { poder, satisfação } \\
\text { Ed apoia uma jovem corredora em suas } \\
\text { maratonas. } \quad \text { Esta melhora } \\
\text { significativamente o seu desempenho. } \\
\rightarrow \text { trabalho, poder, satisfação } \\
\text { Ed interpreta Jimmy à uma senhora que } \\
\text { vive sozinha e que supostamente sofre de } \\
\text { Alzheimer. Jimmy, que era seu marido, já } \\
\text { havia morto. } \rightarrow \text { satisfação, materialidade }\end{array}$ \\
\hline As de paus & $\begin{array}{l}\text { Uma carta de fertilidade } \\
\text { feminina. Denota criação, } \\
\text { gênese, um novo } \\
\text { empreendimento, } \\
\text { atividade, sorte, lucro, } \\
\text { herança, nascimento. }\end{array}$ & $\begin{array}{l}\text { Ed ajuda a uma humilde família } \\
\text { composta somente pela mãe e seus filhos. } \\
\rightarrow \text { fertilidade feminina } \\
\text { Ed empreende um grande evento em } \\
\text { benefício de uma igreja em que } \\
\text { praticamente não havia fiéis } \rightarrow \text { um novo } \\
\text { empreendimento, atividade } \\
\text { Ed faz com que prospere a união, a paz e } \\
\text { a cumplicidade entre dois jovens irmãos } \\
\text { que viviam em confrontos } \rightarrow \text { gênese, } \\
\text { (re)nascimento }\end{array}$ \\
\hline As de espada & $\begin{array}{l}\text { Uma carta vigorosa. Denota } \\
\text { triunfo, conquista, excesso, } \\
\text { bem como um amor ou } \\
\text { ódio muito passional. }\end{array}$ & $\begin{array}{l}\text { Ed leva proporciona um grande momento } \\
\text { de felicidade a uma família em uma } \\
\text { época natalina } \rightarrow \text { triunfo } \\
\text { Ed descobre que sua mãe atraiçoava o seu } \\
\text { pai quando esse estava vivo. Ademais, a } \\
\text { matriarca deprecia tanto o seu falecido } \\
\text { marido quanto o filho, Ed. Apesar disso, } \\
\text { Kennedy ainda conserva os seus } \\
\text { sentimentos de filho por ela. "Faz falta } \\
\text { muito amor para odiar-te assim" } \\
\text { (ZUSAK, 2002, p. 268, tradução nossa). } \\
\text { "Queria dizer-lhe que ainda a amo" } \\
\text { (ZUSAK, 2002, p. } 267 \text {, tradução nossa). } \\
\rightarrow \text { excesso, bem como um amor ou ódio muito } \\
\text { passional. }\end{array}$ \\
\hline As de coração & $\begin{array}{l}\text { O sentido divinatório da } \\
\text { carta envolve a liberação da } \\
\text { emoção bruta, um }\end{array}$ & $\begin{array}{l}\text { Ed desvenda segredos, debruça-se sobre a } \\
\text { privacidade das pessoas mais íntimas a } \\
\text { ele a fim de solucionar os problemas das }\end{array}$ \\
\hline
\end{tabular}




\begin{tabular}{|c|c|c|}
\hline & $\begin{array}{l}\text { relacionamento nascente, o } \\
\text { início de uma viagem de } \\
\text { amor. }\end{array}$ & $\begin{array}{l}\text { mesmas. Essas pessoas são os seus } \\
\text { amigos: Richie, Marv e Audrey. } \\
\text { Ritchie sentia-se bastante incômodo por } \\
\text { nunca ter tido emprego, pois até as } \\
\text { pessoas em que ele acreditava ter menos } \\
\text { competência, tinham-no. } \rightarrow \text { liberação da } \\
\text { emoção bruta } \\
\text { Marv, que sempre era muito tacanho, } \\
\text { tinha um grande motivo para economizar } \\
\text { dinheiro: dar melhor condição de vida ao } \\
\text { seu filho, o qual Marv não o conhecia e, } \\
\text { por problemas familiares, estava } \\
\text { impendido de conhecê-lo e reencontrar o } \\
\text { seu grande amor, a mãe de seu filho. } \\
\rightarrow \quad \text { liberação da emoção bruta, um } \\
\text { relacionamento nascente, o (re)início de uma } \\
\text { viagem de amor. } \\
\text { Audrey, a grande amiga e amor de Marv, } \\
\text { deixa que o sentimento de amor entre os } \\
\text { dois aflore. } \rightarrow \text { liberação da emoção bruta, o } \\
\text { início de uma viagem de amor. }\end{array}$ \\
\hline Coringa & $\begin{array}{l}\text { Representa por tradição o } \\
\text { número } 0 \text { (zero), símbolo } \\
\text { do "tudo ou nada", dos } \\
\text { opostos complementares: } \\
\text { senso e contrassenso, } \\
\text { alegria e tristeza, sabedoria } \\
\text { ou ignorância. } \\
\text { O grande segredo do } \\
\text { curinga é justamente este: o } \\
\text { de um ser dotado de } \\
\text { inteligência e vivacidade } \\
\text { mental por trás da aparência } \\
\text { de tolo. É uma figura alegre } \\
\text { e divertida, como sua } \\
\text { própria razão de ser, mas se } \\
\text { torna de difícil interpretação } \\
\text { quando compreendemos que } \\
\text { sua mensagem vem disfarçada }\end{array}$ & $\begin{array}{l}\text { O último naipe é destinado ao próprio } \\
\text { Kennedy. Momento em que o misterioso } \\
\text { remetente de todos os naipes aparece e } \\
\text { justifica o porquê e o objetivo de todas as } \\
\text { missões. Tais missões tinham o objetivo } \\
\text { de mostrar a Ed que, mesmo ele sendo } \\
\text { uma pessoa aparentemente desprezível, } \\
\text { um jovem qualquer sem aparentes } \\
\text { expectativas da vida, pode ter êxitos nela. } \\
\text { No entanto, por não ter uma identidade } \\
\text { clara, isto é, não apresentar um nome, } \\
\text { esse remetente leva o leitor acreditar em } \\
\text { supostos locutores, os quais se desfazem } \\
\text { ao passo da leitura. Até o final da } \\
\text { narrativa não é revelado nomes. } \\
\text { Trataremos da identidade do emissor } \\
\text { dessas cartas mais adiante neste artigo. }\end{array}$ \\
\hline
\end{tabular}


Tabela 1

Mediante as perspectivas de tais teóricos e das análises apresentadas, podemos afirmar que as personagens Ed Kennedy, Audrey e Marv são sujeitos pósmodernos, assim como a narrativa. Características como a fragmentação, a hibridez, o pluralismo, a autenticidade dos sujeitos, como mostra a tabela 1, revelam a complexidade do ser pós-moderno. Nessa mesma perspectiva, ao explorarmos a configuração da narrativa, vê-se a maneira inovadora e criadora de apresentar esses sujeitos, a qual é marcada pela inusitada e elaborada linguagem para expressá-lo. Em outras palavras, essa elaboração é notória no jogo metalinguístico e nas microhistórias que simultaneamente se aproximam e distanciam-se continuamente.

De acordo com Sousa (2009),

[...] A sociedade pós-moderna abrange um número de jogos de linguagem diferentes e incompatíveis, nos quais cada um apresenta os seus próprios princípios intransferíveis de autolegitimação, marcando assim, a transição do domínio das grandes narrativas para a autonomia fragmentadora das micronarrativas. (SOUSA, 2009, p. 32)

Desse modo, ao utilizar a simbologia da cartomancia, percebe-se a continuação do modernismo como negação à totalidade homogênea na literatura, isto é, da ideologia tradicional, pois o pós-modernismo "procura legitimar a cultura popular ao invés de se desgastar democratizando a cultura de elite" (SOUSA, 2009, p. 31). Isso posto, consideramos que tudo pode tornar-se referência ou alusão na cultura pós-moderna, pois "se os signos culturais e as imagens da mídia formam a realidade, a distinção entre arte e cultura popular desaparece porque os critérios para tal situação não existem mais" (BONNICI, 1999, p. 29). 


\section{CARTAS CRUZADAS: UMA METAFICCÇÃO HISTORIOGRÁFICA}

Linda Hutcheon (1991), grande teórica canadense particularmente conhecida por suas influentes teorias sobre o pós-modernismo, apresenta uma série de características das narrativas pós-modernas. Essa estudiosa afirma que o texto pósmoderno recusa a onisciência e a onipresença em terceira pessoa, em seu lugar, há um envolvimento num diálogo entre uma voz narrativa e o leitor imaginário. Essa voz em Cartas Cruzadas é patenteada pela personagem Ed Kennedy ao longo de toda narrativa, a qual predominantemente apresenta-se na primeira pessoa do singular e caracteriza-se pela interação narrador/personagem e leitor:

Começo a tremer.

Começo a tiritar.

Começo a estremecer-me e a convulsionar-me perante a ideia de matar outro ser humano. A aura que antes me rodeava desapareceu.

A sensação de ser invencível me abandonou e de repente sou consciente de que tenho que fazer isto envolvido unicamente pela minha própria fragilidade humana. Respiro. Quase me vejo no chão. Pergunto-lhes:

Que fariam se estivessem no meu lugar? Digam-me. Eu lhes rogo, digam-me! Mas vocês estão longe daqui. Seus dedos passam por estas estranhas páginas que de algum modo vinculam minha vida com as suas. Seus olhos estão a salvo. Para mim, é aqui. É o momento (ZUSAK, 2002, p. 103-104, tradução nossa).

A essa maneira moderna de escrever, Hutcheon (1991) nomeia "autoficção". "Ficção" porque toda lembrança é ficcionalizante e "auto" porque tal maneira de escrever permite que o autor adote a "natureza de seu personagem ficcional - e não o contrário" (HUTCHEON, 1991, p. 28). Corroborando com esse pensamento, a mencionada teórica categoriza essas narrativas como uma "metaficção historiográfica", em que há o confronto dos paradoxos da representação "fictícia/histórica", do "particular/geral" e do "presente/passado". Ademais, ela 
assegura que essa confrontação é contraditória, pois ainda que ela esteja disposta a recuperar os dois lados da dicotomia, ela se recusa a restaurar ou desintegrar qualquer um dos lados. Retomando a concepção de Hutcheon (1991), ela afirma que as metaficções historiográficas incorporam a autoconsciência teórica sobre a história e a ficção como criações humanas. Essas passam a ser "a base para seu repensar e sua reelaboração das formas e dos conteúdos do passado" (HUTCHEON, 1991, p. 22).

Em Cartas Cruzadas, essa natureza metaficcional chega ao seu ápice no final da narrativa no momento de revelar ao leitor e ao próprio personagem Ed Kennedy o remetente dos naipes que esse jovem recebia. Esse remetente chega até o fim da narrativa sem uma identidade clara e palpável. Ao longo da obra, a história nos conduz a dois iniciais suspeitos: o assaltante do banco, que no início da narrativa ameaçou Kennedy com as palavras "És um homem morto", e o pai de Ed Kennedy, que não aparece na narrativa, pois já havia morto há seis meses, na cronologia da história. Esse seria um recurso para ludibriar o leitor, levando-o insaciavelmente a seguir a leitura.

Ao analisar as circunstâncias em que se deu o desfecho da narrativa, percebemos que "És um homem morto. Espera e verás" (ZUSAK, 2002, p. 48, tradução nossa) tem um valor metafórico, isto é, tem uma concepção de previsibilidade, o que contradiz com a acepção de sujeito pós-moderno, mas que ao mesmo tempo corrobora com ela, uma vez que ele é paradoxal, contraditório. Em outras palavras, todas as missões e ações do protagonista já estavam previstas pelo remetente dos naipes.

Esse enigmático remetente da história sabia desde o princípio tudo o que iria transcorrer ao longo da narrativa. Isso se concretiza pela pasta amarela, a qual foi entregue a Ed Kennedy no penúltimo capítulo, na qual descrevia minuciosamente tudo o que Kennedy havia passado. Tal momento coloca em crise a identidade de Kennedy e em questionamento a fronteira entre o ficcional e o não ficcional: 
Levanto-me atônito, perplexo, comovido.

Finalmente consigo falar.

- Sou real?

Apenas detém-se a meditá-lo. Não precisa disso.

- Olha a pasta -diz -. Em direção ao final. ¿Vês?

Está escrito com grandes letras no dorso de um suporte de copos de papelão. Sua resposta está escrita com tinta preta. Diz: "Naturalmente que és real, como todo pensamento ou história que um autor decide contar. És real enquanto a estejas vivendo" (ZUSAK, 2002, p. 375, tradução nossa).

Desse modo, as únicas informações que Ed tem desse remetente são as suas características físicas:

Tem o cabelo castanho, bastante curto, está mais ou menos abaixo da estatura mediana e veste camisa, calça jeans preta, tênis azuis. Tem mais pinta de garoto que de homem, mas quando fala, sua voz não lembra nada a de um garoto (ZUSAK, 2002, p. 374, tradução nossa).

Ainda no penúltimo capítulo, quando Ed está frente a frente com o seu remetente, a personagem tem o benefício do recurso visual, o qual o leitor não é contemplado para desvendá-lo - o que leva o leitor à curiosidade, à expectativa. Também nessa ocasião, o remetente conta ao jovem Kennedy que estava presente em todas as ocasiões da vida de Ed e que organizou tudo o que lhe aconteceu nos últimos meses. Além disso, afirma que o único propósito das missões era mostrar-lhe que, se ele, Ed Kennedy, "a mediocridade personificada" (ZUSAK, 2002, p. 374, tradução nossa) é capaz de ajudar a todas as pessoas as quais ele ajudou, qualquer um também o pode fazê-lo. E que tudo o que lhe acontecerá também está previsto.

Folheio a pasta e encontro o que me contou o homem. Estão anotadas todas as ideias e esboçados todos os personagens. Há anotações juntas com grampos. Rascunho que dizem e desdizem.

Passam horas.

Seguidas de dias (ZUSAK, 2002, p. 377, tradução nossa). 
Para surpresa do leitor, na antepenúltima página da narrativa, há as seguintes indagações de Ed Kennedy:

Pergunto-me como se chama [o remetente das missões], ainda que não me reste dúvida de que não demorarei em averiguá-lo.

Escreveu sobre isto, o sacana, estou certo disso. Não deixou nada de fora.

Enquanto se distancia, tira um caderninho do seu bolso e faz algumas anotações.

Isso me leva a pensar que talvez também eu devesse escrever sobre o que passou. Afinal de contas, sou eu quem fez todo o trabalho.

Começaria com o assalto ao banco.

Algo como: "O homem da pistola inútil".

Não obstante, existem muitas possibilidades de que o cara tenha adiantado isso.

Será seu nome o que aparecerá na capa do livro que contém todas estas palavras, não o meu.

Ele levará todo o crédito.

Ou descrédito, se faz um mau trabalho.

Mas recordem que fui eu e não ele quem deu vida a estas páginas. Fui eu que...

Bom, vou ver se me calo de uma vez (ZUSAK, 2002, p. 376, tradução nossa).

Esse trecho nos leva a inferir, enquanto leitores, que o remetente de todos os naipes não é nenhuma das personagens da história, mas uma alusão ao próprio autor do romance: Markus Zusak. Correlacionando as palavras de Ed - o trecho acima exposto - à nossa análise, é evidente que dita personagem realiza indagações a fim de descobrir o nome do tal homem que a ele enviou os naipes para as missões, expresso nas primeiras linhas. Assim sendo, elencamos três pontos cruciais que nos levam a tal interpretação:

I. De fato, a primeira frase da narrativa, que inicia a primeira parte do romance é: “O homem da pistola é um inútil." (ZUSAK, 2002, p. 11, tradução nossa), a qual Ed afirma que começaria a narrativa se por ele tal obra fosse escrita; 


\section{Revista Letras Raras}

ISSN: 2317-2347 - Vol. 7, Ano 4, No 2 - 2015

II. Como sabido, o autor de Cartas Cruzadas é o australiano MarkusZusak, o que nos possibilita uma pressuposição ao enunciado “Será o seu nome o que vai aparecer na capa do livro que contém todas as palavras, não o meu" (ver figura 1);

III. Por fim, correlacionando as características físicas do referido homem expressas por Ed Kennedy às características reais do autor Markus Zusak, elas se assemelham claramente ao seu estilo e atributos físicos (ver figuras2 e 3).

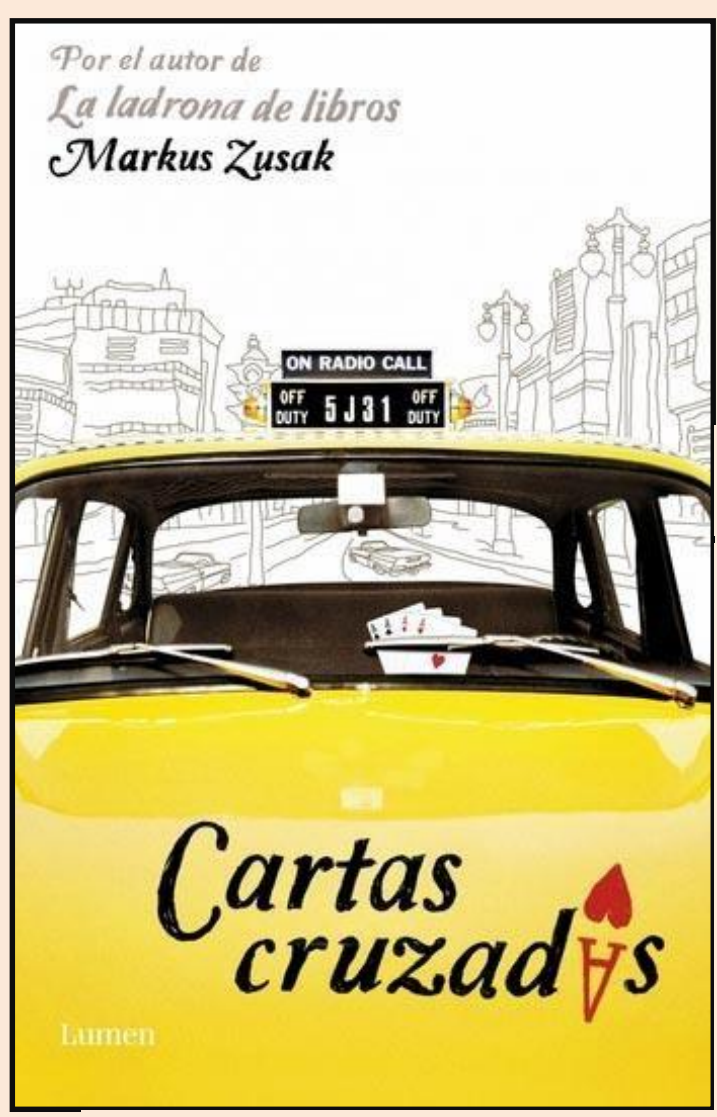

Figura 1 - Cartas Cruzadas

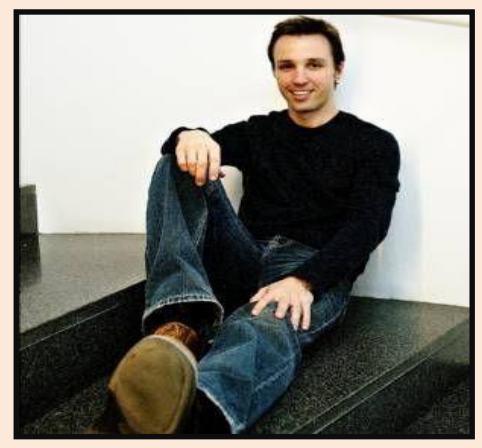

Figura 2 - Markus Zusak

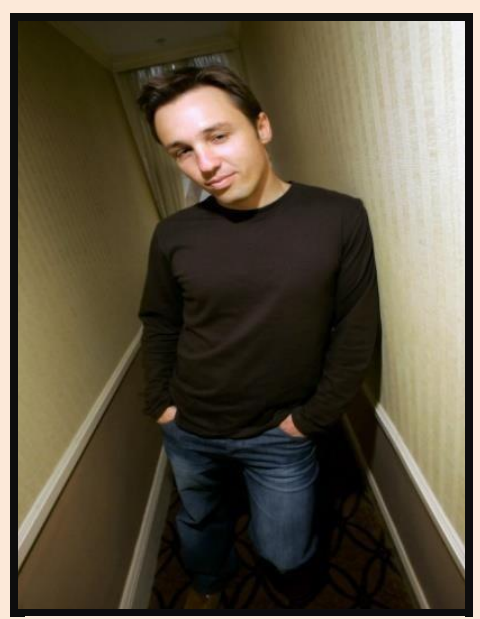

Figura 3 - Markus Zusa s

Deste modo, é certo que a fronteira entre o interior (livro/ficção) e o exterior (autor/leitor) é demasiado tênue, quase inexistente, a qual torna o romance inovador e próprio de uma produção pós-moderna. Os jogos de linguagem estão elaborados 
de tal forma que o romance chega ao fim sem que o leitor tenha às claras quem é o indecifrável remetente dos naipes.

No universo pós-modernista, a identidade real é trocada por um simulacro, no qual a simulação é mais real que a realidade. Assim, há uma hiper-realização do mundo, no qual tudo é um espetáculo. Ou seja, no pós-modernismo há uma tendência à simulação do real. Nas palavras do teórico brasileiro Jair Ferreira dos Santos (2004), temos uma literatura em que "não é para se acreditar no que está sendo dito, não é um retrato da realidade, mas um jogo com a própria literatura, suas formas a serem destruídas, sua história a ser retomada de maneira irônica e alegre" (SANTOS, 2004, p. 24). Nesse sentido, a arranjada configuração dessa narrativa seria uma estratégia para ludibriar o leitor e, assim, seduzi-lo, prendê-lo, levando-o a caminhos do texto em que ele já não queira desviar dele - pelo menos enquanto a leitura durar. Logo, essas pistas seriam uma armadilha para o leitor.

Nas palavras de Hutcheon (1991), o pós-modernismo

se caracteriza por esse tipo de incredulidade em relação às narrativasmestras ou metanarrativas: aqueles que se queixam da "perda de sentido" no mundo ou na arte estão realmente lamentando o fato de que o conhecimento já não é esse tipo de conhecimento basicamente narrativo. (HUTCHEON, 1991, p. 23).

\section{CARTAS CRUZADAS: UM EXEMPLO DE LITERATURA CONTEMPORÂNEA}

Para tratar da qualidade literária do romance contemporâneo em estudo, fazse necessário que definamos o que consideraremos como literatura. É certo que até os dias atuais classificar uma obra como "literatura" é uma atividade laboriosa, visto que o sentido moderno de literatura está estreitamente ligado à noção romântica, isto é, "literatura" são os grandes escritores. Diante desse conceito, negligencia-se a complexidade dos níveis de literatura, assim como há níveis de língua numa sociedade. Logo, nesse sentido restrito, a literatura popular não seria considerada 
como tal, como literatura. (COMPAGNON, 2006). Portanto, consideramos o conceito de literatura como uma realidade provisória, "porque não há essência da literatura, ela é uma realidade complexa, heterogênea, mutável" (COMPAGNON, p. 44), visto que ao longo dos tempos, a fronteira entre o literário e o não literário variou consideravelmente, segundo as épocas e culturas.

Para Aristóteles, por exemplo, a arte da "coisa sem nome", a literatura, era somente o gênero épico e o dramático, excluindo-se o gênero lírico. No entanto, ao longo do século XIX, por literatura compreendeu-se o romance, o teatro e a poesia que, na tríade aristotélica, seriam os gêneros épico, dramático e lírico, respectivamente. Apoiando-nos na perspectiva do francês Antoine Compagnon em seu livro O demônio da teoria, acreditamos que,

[...] evidentemente, identificar a literatura com o valor literário (os grandes escritores) é, ao mesmo tempo, negar (de fato e de direito) o valor do resto dos romances, dramas e poemas, e, de modo mais geral, de outros gêneros de verso e de prosa. Todo julgamento de valor repousa num atestado de exclusão. Dizer que um texto é literário, subentende sempre que um outro não é (COMPAGNON, 2006, p. 33)

É notório que a configuração de Cartas Cruzadas está permeada por uma linguagem que se diferencia da linguagem cotidiana. Essa é a linguagem literária (COMPAGNON, 2006). Se é literária, logo, é literatura. No entanto, em Cartas Cruzadas, a linguagem também se aproxima da linguagem cotidiana, que a caracteriza como um texto pós-moderno/contemporâneo. De acordo com esse autor, a linguagem literária cultiva sua própria opacidade, ou seja, ela é "intransitiva", "perceptível"; ela é mais "sistemática", "organizada", "coerente", "densa", "complexa"; o seu uso literário da língua é "imaginário", estético". Em suma, a literatura explora, sem fim prático, o "material linguístico". Ratificando toda a análise neste artigo realizada, assim o faz Cartas Cruzadas. Nessa perspectiva, não há motivos para que não classifiquemos o romance em estudo como uma boa literatura, 
ainda que a sua configuração não acompanhe as perspectivas tradicionais. Como explica Compagnon (2006),

\begin{abstract}
A literatura confirma um consenso, mas produz também a dissensão, o novo, a ruptura. [...] Do ponto de vista da função, chega-se também a uma aporia: a literatura pode estar de acordo com a sociedade, mas também em desacordo; pode acompanhar o movimento, mas também precedê-lo. (COMPAGNON, 2006, p. 37)
\end{abstract}

Diante disso, acreditamos que textos contemporâneos como Cartas Cruzadas devem ser inseridos na composição curricular das escolas regulares e serem passíveis de recorrentes estudos na Academia. No entanto, segundo Compagnon (2006), a sociedade decide se certos textos são literários ou não fora de seus contextos originais, somente pelo uso que faz dos textos, sem remetê-los necessariamente a seu contexto de origem. Isso posto, hoje, infelizmente, a definição de literatura "é sempre uma preferência (um preconceito) erigido em universal" (COMPAGNON, 2006, p. 44), que paulatinamente deve ser erradicado.

\title{
CONSIDERAÇÕES FINAIS
}

A resposta pós-moderna ao modernismo consiste em reconhecer o passado, já que não pode ser destruído porque a sua destruição leva ao silêncio, deve ser revisitado com ironia, de maneira não inocente.

(Umberto Eco)

Ao analisarmos o romance Cartas Cruzadas procuramos verificar a hibridez e a multiplicidade do sujeito pós-moderno nas personagens estudadas e, por conseguinte, a riqueza literária dessa obra contemporânea, que, comumente, não é prestigiada na Academia. A partir de nossa compreensão, as características da literatura pós-moderna estão claramente presentes, as quais são complexas e contraditórias. A simbologia na intertextualidade, a diluição da identidade frente às 
inúmeras experiências de ruptura, a recusa dos modelos modernos da literatura, a ironia na configuração da narrativa, o mistério na composição do desfecho do romance em que há o jogo entre realidade e ficção são algumas das características enriquecedoras para a significação estética zusakiana. Através das personagens imprecisas e multifacetas que são Ed Kennedy, Marv e Audrey, o escritor australiano constrói, mais precisamente em Ed Kennedy, o reflexo do homem da pósmodernidade: urbano, anônimo e solitário. Quanto ao grande enigma do emissor dos naipes, Zusak "desconstrói" o gênero do enigma, uma vez que ele desvia o foco do romance, desfaz a possibilidade de ser uma das personagens supostamente esperada pelo leitor, ludibriando-o. Dessa forma, o autor quebra essas expectativas e dá ênfase à autorreflexividade literária, ao confronto entre realidade e ficção.

Nesse sentido, nosso objetivo ao longo do estudo não foi responder perguntas sobre o que é pós-modernismo, uma vez que a ideia desse movimento artístico, estético e cultural, como pudemos refletir ao longo do artigo, prossegue sem deixar muito claro o que significa esse fenômeno na realidade, "pois este não apresenta propostas definidas" (SOUSA, 2009, p.94). Tampouco buscamos comprovar a "boa qualidade" literária da obra pós-moderna em análise. O que propusemos é, a partir da análise aqui realizada, contribuir para uma nova "cara" dos estudos literários, isto é, reconhecer as obras contemporâneas como literatura a fim de impulsionar estudos acerca delas e que as barreiras para a sua presença na Academia e nas escolas regulares sejam, pouco a pouco, dissolvidas; e, consequentemente, os novos autores. Ao afirmar isso, estamos considerando que há vários níveis de literatura, sem desconsiderá-las ou inferiorizá-las umas às outras.

Em suma, Cartas Cruzadas não é simplesmente um romance best-seller, mas um texto em que diversas histórias se circunscrevem, que várias interpretações coexistem e que nuances singulares se entrelaçam, revelando-nos uma realidade. Um texto que só a literatura pode oferecer-nos. Um texto pós-moderno. 


\section{REFERÊNCIAS}

BONNICI, Thomas. A teoria do pós-modernismo e a sociedade. In: Mimesis, Bauru, v. 20, n. 2, p. 25-37, 1999.

BRAIT, Beth. O faz-de-conta das personagens. In: A personagem. 3. ed. São Paulo: Ática, p. 8-18, 1985.

CABRAL, Newton Darwin de Andrade. O paradigma pós-moderno: política e escrita da história. In: Revista Symposiu M, Recife, ano 3, n. especial, p. 10-18, jun. 1999.

COMPAGNON, Antoine. A literatura. In: . O demônio da teoria: literatura e senso comum. 3. ed. Belo Horizonte: Ed. UFMG, p. 29-45, 2006.

COUTO, Edvaldo Souza. O homem satélite: estética e mutações do corpo da sociedade tecnológica. Injuí: Unijuí, 2000.

ECO, Umberto. Pós-escrito a O Nome da Rosa. Tradução de Letizia Zini Antunes e Álvaro Lorencini. 4. ed. Rio de Janeiro: Nova Fronteira, 1985.

GOTACH. Disponível em: <http://gotach.com.br/baralhocigano/significados-php/>. Acesso em: 2 abr. 2013.

HALL, Stuart. A identidade cultural na pós-modernidade. 9. ed. Rio de Janeiro: DP\&A, 2004.

HUCTHEON, Linda. Poética do pós-modernismo: história, teoria e ficção. Tradução de Ricardo Cruz. Rio de Janeiro: Imago, 1991.

JAMESON, Fredic. Pós-modernidade e sociedade de consumo. Tradução de Vinicius Dantas. In: Novos Estudos CEPRAB, São Paulo, n. 12, p. 16-26, jun. 2005.

SANTOS, Jair Ferreira dos. O que é pós-moderno. São Paulo: Brasiliense, 1983.

SOUZA, Eneida Maria de. Crítica cult. Belo Horizonte: Editora UFMG, 2002.

SOUSA, Michelli Cristina. Escrita e fragmentação da identidade contemporânea: a trilogia de Nova York de Paul Auster. 2009. 141 f. Dissertação(Mestrado em Letras) - 
Programa de Mestrado em Letras, Universidade Federal de São João del-Rei, São João del-Rei, 2009.

TEIXEIRA COELHO, José. Modos culturais pós-modernos. In: . Moderno pós moderno: modo e versões. 5. ed. São Paulo: Iluminuras, 2005, p. 172-192.

. Pós-modernidade: "paradigma de todas as submissões"? In: Moderno

pós moderno: modo e versões. 5. ed. São Paulo: Iluminuras, 2005, p. 213-222.

TOPGYN. Disponível em: <http://www.topgyn.com.br/conso17/cartas/> Acesso em: 29 mar. 2013.

\section{Créditos das imagens:}

Figura 1. Disponível em: <http://www.lasemana.es/libros/portadas/fp1442.jpg> Acesso em: 2 abr. 2013.

Figura2. Disponível em: <http://thelitconnection.files.wordpress.com/2008/03/mzsitting.jpg> Acesso em: 2 abr. 2013.

Figura 3. Disponível em: <http://media.pennlive.com/go/photo/-601863106042006jpgc8b77b7bb0d75a06.jpg> Acesso em: 2 abr. 2013. 